\title{
Senancour, Obermann. Dernière version
}

\section{Eric Francalanza}

\section{(2) OpenEdition}

\section{Journals}

\section{Édition électronique}

URL : https://journals.openedition.org/studifrancesi/39548

DOI : 10.4000/studifrancesi.39548

ISSN : 2427-5856

\section{Éditeur}

Rosenberg \& Sellier

\section{Édition imprimée}

Date de publication : 1 décembre 2004

Pagination : 386

ISSN : 0039-2944

\section{Référence électronique}

Eric Francalanza, «Senancour, Obermann. Dernière version», Studi Francesi [En ligne], 143 (XLVIII | II) | 2004, mis en ligne le 30 novembre 2015, consulté le 19 mai 2021. URL : http://

journals.openedition.org/studifrancesi/39548; DOI : https://doi.org/10.4000/studifrancesi.39548

Ce document a été généré automatiquement le 19 mai 2021.

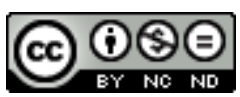

Studi Francesi è distribuita con Licenza Creative Commons Attribuzione - Non commerciale - Non opere derivate 4.0 Internazionale. 


\title{
Senancour, Obermann. Dernière version
}

\author{
Eric Francalanza
}

\section{RÉFÉRENCE}

SENANCOUR, Obermann. Dernière version, introduction, établissement du texte, variantes et notes par BÉATRICE DIDIER, Paris, Honoré Champion, 2003 («Textes de littérature moderne et contemporaine», $\left.\mathrm{n}^{\circ} 45\right)$ pp. 491.

1 Béatrice Didier nous procure une édition critique d'Obermann à laquelle elle devait songer depuis longtemps déjà: pour preuve ses deux grands ouvrages, L'Imaginaire de Senancour (Corti, 1966) et Senancour romancier (SEDES, 1985). Cette édition se présente donc comme un travail longuement médité, et cela se manifeste sans pesanteur dans l'ensemble de l'ouvrage.

2 Son entreprise s'appuie tout d'abord sur un texte de base demeuré jusque-là inédit. C'est en somme une première version de la «dernière version» d'Obermann que nous avons désormais entre les mains. Senancour projetait d'éditer ses CEuvres complètes et avait commencé à remanier son édition de 1840. Aussi est-ce à partir des notes manuscrites que Senancour a portées dans cette édition qu'a travaillé Béatrice Didier. Les variantes des éditions $(1804,1833$ et 1840) sont relevées avec rigueur à la fin de l'ouvrage, non sans fournir également en appendice les «Notes» dont Senancour avait pourvu son texte lors de la publication de 1833, ainsi que l'idylle grecque qui figurait dans la version d'origine, enlevée lors de la publication de 1840. Bref: l'édition de B.Didier se révèle un très appréciable outil de travail. On regrette pourtant un seul manque dans cet apparat critique déjà fort riche: que ne soient pas précisés les passages que Senancour avait glissés dans les Rêveries ou dans De l'Amour après l'échec de 1804. Il suffisait de recourir à l'édition Michaut (1912-13), que B.Didier avoue par ailleurs avoir utilisée pour le relevé des variantes. On aurait également aimé feuilleter un index des noms, des œuvres et des thèmes. Mais sans doute l'ouvrage est-il déjà 
assez copieux pour se passer de ces menues indications qui n'apportent qu'une matière périphérique à l'histoire du texte et à sa compréhension. Enfin, on a du mal à comprendre pourquoi le texte est à ce point chargé de fautes de langue et de typographie qui n'ont rien à voir avec quelque édition d'époque. En revanche, une bibliographie solide complète heureusement ce travail.

D'ailleurs, cette impression de solidité se confirme à la lecture de la préface, fort belle synthèse qui éclaire magistralement l'œuvre de Senancour. Elle constitue un panorama concis de l'itinéraire moral et intellectuel du romancier et de la poétique d'Obermann. L'analyse s'ouvre en effet par un récapitulatif biographique et littéraire qui évite de présenter le roman comme absolument indépendant des autres ouvrages, tout en posant les jalons d'une compréhension dynamique de l'œuvre et de son évolution. Obermann relève d'un genre hybride, dont l'inspiration se situe à la croisée des lettres familières et philosophiques, du guide de voyage, du roman épistolaire et du journal intime. Mais l'originalité du roman apparaît aussi dans le rapport que le texte entretient avec l'histoire et l'évolution du siècle. La question de la Révolution, absente de la diégèse, donne, par exemple, une forme particulière à l'œuvre, travaillant jusqu'au sens du rythme, jusqu'à l'interprétation philosophique, jusqu'au style. On se plaît encore à lire les notes érudites qui éclairent le texte et en circonscrivent l'intérêt historique et littéraire. Cette approche contrevient ainsi à certaines idées reçues que B.Didier combat avec une grande efficacité: tout d'abord, l'activité littéraire de Senancour n'a jamais connu de période creuse -et de rappeler la figure d'un Senancour journaliste; d'autre part, les remaniements qu'opère Senancour suivent plus qu'on ne le pense l'évolution esthétique du temps. Ce sont là, on le comprend, les deux raisons fondamentales pour lesquelles B. Didier a choisi de publier cette "dernière», et nouvelle, version de l'œuvre. 